\title{
Decomposition of Carbon Disulfide Using Dielectric Barrier Discharge Plasma Coupled with Limonite and Siderite Supported Bismuth Vanadate Catalysts
}

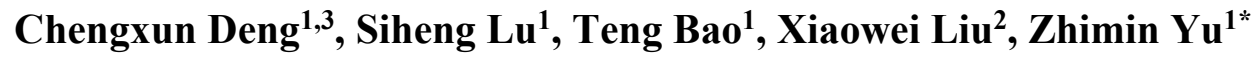 \\ ${ }^{1}$ Department of Biological and Environmental Engineering, Hefei University, Hefei 230022, China \\ ${ }^{2}$ School of Resources and Environmental Engineering, Hefei University of Technology, Hefei 230009, China \\ ${ }^{3}$ Hefei Jietong Environmental Technology Co., Ltd., Hefei 230088, China
}

\begin{abstract}
This paper presents the catalytic decomposition of $\mathrm{CS}_{2}$ using dielectric barrier discharge plasma coupled with novel limonite or siderite supported $\mathrm{BiVO}_{4}$ composite material (limonite/ $\mathrm{BiVO}_{4}$ or siderite/ $\mathrm{BiVO}$ ) prepared via a hydrothermal method. The crystalline structure, surface morphology, gas adsorption properties, and surface chemistry of the catalysts are characterized. The results show that $\mathrm{BiVO}_{4}$ supported on the limonite or siderite is highly dispersible, which increases its active site. In addition, $\mathrm{CS}_{2}$ decomposition efficiencies obtained using catalysts fabricated with various $\mathrm{Fe} / \mathrm{Bi}$ ratios and calcination temperatures are experimentally evaluated. The result show that the maximum $\mathrm{CS}_{2}$ decomposition efficiencies are obtained using catalysts calcined at $350^{\circ} \mathrm{C}$ with limonite $/ \mathrm{BiVO}_{4}$ and siderite $/ \mathrm{BiVO}_{4}$ mass ratios of $3: 7$, which respectively yield $\mathrm{CS}_{2}$ decomposition efficiencies are $11.9 \%$ and $13.2 \%$ greater than that obtained with dielectric barrier discharge treatment alone. The differences in the $\mathrm{CS}_{2}$ decomposition efficiencies of the two types of supported catalysts may be due to the chemical and physical differences between limonite and siderite, including the oxidation states of iron and the surface morphology of the iron ores.
\end{abstract}

Keywords: Dielectric barrier discharge; Supported bismuth vanadate; Carbon disulfide; Catalytic decomposition.

\section{INTRODUCTION}

Carbon disulfide $\left(\mathrm{CS}_{2}\right)$ is an odorous sulfur compound that has been widely used as important feedstock in the rubber, metallurgy, and viscose fiber industries. However, $\mathrm{CS}_{2}$ emissions promote photochemical reactions in the stratosphere that represent the primary source of acid rain, which can have harmful effects on the environment and public health (Bates et al., 1992; Tabari et al., 2017). Moreover, $\mathrm{CS}_{2}$ exposure has been attributed to accelerated atherosclerosis and coronary artery disease (Price et al., 1997; Jia et al., 2017). Common methods of treating $\mathrm{CS}_{2}$ emissions include adsorption, liquid absorption, condensation, thermo-decomposition, and plasma-based decomposition (Rojo et al., 2010; Pham et al., 2016; Laing et al., 2017). In recent years, plasma-based decomposition technology employing dielectric barrier discharge (DBD) has received considerable attention in the field of hazardous gas treatment due to its significant advantages over conventional $\mathrm{CS}_{2}$ treatments, such as low cost and milder operation $\mathrm{s}$

\footnotetext{
${ }^{*}$ Corresponding author.

Tel.: 0-86-0551-62158447

E-mail address: yuzhimin@hfuu.edu.cn
}

conditions, and reduced energy and material consumption (Rojo et al., 2010; Zhu et al., 2013; Albertos et al., 2017; Yang et al., 2017a). However, the decomposition processes in DBD plasma treatment often involve incomplete oxidation reactions, leading to the potential generation of toxic byproducts (Holzer et al., 2002; Li et al., 2017b). This can be addressed by combining plasma decomposition treatment with catalytic processes, which can also significantly improve the energy efficiencies and decomposition performances of the treatments (Krawczyk and Mlotek, 2001; Futamura, 2005; Liu and Liu, 2011; Vandenbroucke et al., 2011; Kirkpatrick et al., 2012). At present, bismuth vanadate $\left(\mathrm{BiVO}_{4}\right)$ supported catalysts have been widely used as excellent photocatalysts for waste gas degradation applications. However, the synergistic catalytic treatment of waste gases by combined $\mathrm{BiVO}_{4}$-supported catalysts and DBD processes has not been widely studied. As such, it warrants additional attention.

$\mathrm{BiVO}_{4}$ is a new type of photocatalyst that possesses a narrow band gap, good visible light absorption, and stable photo-corrosion resistance (Singh et al., 2016). In addition, $\mathrm{BiVO}_{4}$ can be converted between three different crystal phases, including tetragonal zircon (z-t), monoclinic scheelite (s-m), and tetragonal scheelite (s-t). The z-t and s-m phases of $\mathrm{BiVO}_{4}$ possess band gaps of $2.9 \mathrm{eV}$ and $2.4 \mathrm{eV}$, respectively. As such, the z-t phase of $\mathrm{BiVO}_{4}$ exhibits optical absorption bands in the ultraviolet (UV) region, while the s-m 
phase exhibits strong optical absorption bands in both the UV and visible regions. This is consistent with the observation that the s-m phase exhibits the highest photocatalytic activity of the three crystalline phases of $\mathrm{BiVO}_{4}$ (Liu et al., 2016). However, the photocatalytic activity of the s-m phase is limited by the relatively high recombination rate of electron-hole pairs generated in the photolytic process. This has been addressed in many studies by integrating $\mathrm{BiVO}_{4}$ with supporting materials. For example, Li et al. (2015) and Cheng et al. (2018) prepared novel hetero-structured $\mathrm{FeVO}_{4} / \mathrm{BiVO}_{4}$ composites via a hydrothermal method, and revealed that the photocatalytic activities of the composites are significantly greater than those of either material alone. Chen et al. (2017a), Wang et al. (2017) and Xiao et al. (2018) developed a $\mathrm{Cu} / \mathrm{BiVO}_{4}$ composite photocatalyst that provided an increased photocatalytic activity relative to that of $\mathrm{BiVO}_{4}$ alone under visible light irradiation. This was speculated to be due to the efficient separation of electronhole pairs in $\mathrm{Cu} / \mathrm{BiVO}_{4}$. The previous studies have established that the photocatalytic activity of $\mathrm{BiVO}_{4}$ is advantageously affected by various properties of the supporting materials, such as nanostructures, high surface area, and high chemical activity (Wang et al., 2017; Wang et al., 2019a, b). These properties are possessed by a number of naturally occurring mineral materials, particularly iron ores, that are widely available and inexpensive (Li et al., 2017a), and are therefore ideal supporting materials for enhancing the photocatalytic activity $\mathrm{BiVO}_{4}$ for use in large-scale hazardous gas treatment applications.

Siderite $\left(\mathrm{FeCO}_{3}\right)$ is a traditional iron mineral resource used in steel smelting. China's siderite resources, with reserves of 2 billion tons, are especially abundant. However, only $10 \%$ of the country's siderite reserves have been utilized thus far (Xing et al., 2017; Huang et al., 2017). Limonite is widely present in the epigenetic oxidizing environment and one of the most important components of surface and biochemical activity in soils and sediments (Zou et al., 2013; Zhao et al., 2018).

The present study presents the catalytic decomposition of $\mathrm{CS}_{2}$ using DBD plasma coupled with novel limonite (main component: $\mathrm{FeO}(\mathrm{OH})$ ) and siderite (main component: $\mathrm{FeCO}_{3}$ ) supported $\mathrm{BiVO}_{4}$ composite catalysts prepared via a hydrothermal method. The catalysts are subjected to detailed characterization, including their crystalline structure, surface morphology, gas adsorption properties, and surface chemistry. The $\mathrm{CS}_{2}$ decomposition efficiencies obtained using catalysts fabricated with various $\mathrm{Bi} / \mathrm{Fe}$ ratios and calcination temperatures are experimentally evaluated. The results demonstrate that the optimum supported $\mathrm{BiVO}_{4}$ catalysts obtain $\mathrm{CS}_{2}$ decomposition efficiencies that are substantially greater than that obtained with non-catalyst DBD plasma treatment. The differences in the $\mathrm{CS}_{2}$ decomposition efficiencies of the two types of supported catalysts are investigated based on the characterization results.

\section{METHODS}

\section{Ores and Chemicals}

We obtained limonite and siderite rock materials from
Tongling mine, Anhui Province, China. The limonite mainly consists goethite, manganese oxides, and iron (III) oxide hydroxides $(\alpha-\mathrm{FeOOH})$, and bears a porous honeycomb structure generated via the weathering of crystals containing siderite and quartz (Zou et al., 2013). The siderite is formed of sedimentary hematite and metamorphic iron ore deposits, and includes a main fraction of $\mathrm{FeCO}_{3}$ along with magnesium and manganese elements (Liang et al., 2015). After crushing, the ore was ground into a fine powder and sifted through a 200 mesh sieve. All chemicals were purchased from commercial sources, and were used without further purification. Copper acetate monohydrate, ethylenediamine, triethanolamine, hydrochloric acid, and nitric acid were purchased as analytical grade, and $\mathrm{CS}_{2}$ and ethanol were purchased with a $99 \%$ purity.

\section{Catalyst Preparation}

Composite catalysts with limonite/ $\mathrm{BiVO}_{4}$ and siderite $/ \mathrm{BiVO}_{4}$ mass ratios of 1:9, 3:7, 5:5, 3:7, and 9:1 were synthesized via a previously reported hydrothermal method (Chen et al., 2018), filtered through 200 mesh sieves, and calcined at different temperatures of $250^{\circ} \mathrm{C}, 350^{\circ} \mathrm{C}, 450^{\circ} \mathrm{C}$, and $550^{\circ} \mathrm{C}$. The hydrothermal synthesis method employed can be briefly outlined as follows. Typically, $\mathrm{Bi}\left(\mathrm{NO}_{3}\right)_{3} \cdot 5 \mathrm{H}_{2} \mathrm{O}$ $(2.43 \mathrm{~g}, 5.0 \mathrm{mmol})$ was added with stirring to an aqueous $\mathrm{HNO}_{3}$ solution $(15 \mathrm{~mL}, 2.0 \mathrm{~mol} \mathrm{~L}-1)$. The specific iron ore material was then added in an amount based on the specific mass ratio. The mixture was stirred for $0.5 \mathrm{~h}$, yielding Solution A. Solution B was obtained by dissolving $\mathrm{NH}_{4} \mathrm{VO}_{3}$ $(0.58 \mathrm{~g}, 5.0 \mathrm{mmol})$ with stirring in the aqueous $\mathrm{NaOH}$ solution $\left(15 \mathrm{~mL}, 2.0 \mathrm{~mol} \mathrm{~L}^{-1}\right)$. Solution B was slowly added to Solution A under vigorous stirring. The $\mathrm{pH}$ of the mixture was adjusted to 5 using an aqueous $\mathrm{HCl}$ solution $\left(2 \mathrm{~mol} \mathrm{~L}^{-1}\right)$. The mixture was stirred for $0.5 \mathrm{~h}$, and transferred to a stainless steel autoclave where it was heated at $180^{\circ} \mathrm{C}$ for $12 \mathrm{~h}$. The mixture was filtered, and the solid component obtained was washed with distilled water and ethanol. The solid was then dried in a conventional oven at $80^{\circ} \mathrm{C}$ for $10 \mathrm{~h}$, and calcined at different temperatures for $2 \mathrm{~h}$ in a muffle furnace to obtain limonite $/ \mathrm{BiVO}_{4}$ or siderite $/ \mathrm{BiVO}_{4}$ composite catalysts.

\section{Characterization Methods}

The crystallographic properties of the limonite/BiVO and siderite/BiVO $\mathrm{BV}_{4}$ composite catalysts were examined by $\mathrm{X}$-ray diffraction (XRD) using a Shimadzu D/Max-rB automatic $X$-ray diffractometer in a $2 \theta$ range of $3^{\circ}$ to $70^{\circ}$ in $3^{\circ} \mathrm{min}^{-1}$. The specific surface areas, $\mathrm{N}_{2}$ adsorption, and pore sizes of the catalysts were determined using the low temperature $\mathrm{N}_{2}$ adsorption volumetric method conducted on a Rigaku D/max-2200/PC X-ray diffractometer with approximately $0.3 \mathrm{~g}$ of solid sample at a detection temperature of $30.4^{\circ} \mathrm{C}$, a cold free space of $48.7 \mathrm{~cm}^{3}$, and a degas temperature of $160^{\circ} \mathrm{C}$. Scanning electron microscopy (SEM) was conducted using a HITACHI SU-70 analytical ultra-high resolution Schottky thermal field emission scanning electron microscope to analyze the surface microstructure of catalysts after calcination. The surface elements, oxidation states, and bonding environments of the calcined catalysts were analyzed using X-ray photoelectron spectroscopy (XPS) 
conducted on a CasaXPS, and XPSPEAK41 was used to conduct peak analysis.

\section{Dielectric Barrier Discharge Plasma}

The plasma reactor employed in this study was the standard cylindrical type DBD reactor illustrated in Fig. 1(a). The DBD reactor was customized by the research team. The reactor included two coaxial fused quartz barriers. The outer barrier was a fused quartz tube with an outer diameter of $25 \mathrm{~mm}$ and a wall thickness of $1 \mathrm{~mm}$. The inner barrier was a fused quartz tube with an outer diameter of $7 \mathrm{~mm}$ and a wall thickness of $1.5 \mathrm{~mm}$. The length of the reactor was $180 \mathrm{~mm}$. The inner electrode was a solid copper rod with a diameter of $3 \mathrm{~mm}$. The outer electrode was composed of a $10 \mathrm{~mm}$ band of copper foil wrapped around the external side of the quartz glass tube forming the outer barrier, as shown in Fig. 1(a). The catalyst was first ground and filtered through a 100 mesh sieve, and $1.2 \mathrm{~g}$ of the sieved catalyst was mixed with absolute ethanol. The resulting slurry was then applied to the inner surface of an encasing tube and dried at $85^{\circ} \mathrm{C}$ in a conventional oven. The encasing tube had an outer diameter of $22 \mathrm{~mm}$ and a wall thickness of $1 \mathrm{~mm}$, and was positioned coaxially between the inner and outer barriers of the DBD reactor, as illustrated in Fig. 1(b). Simulated flue gas containing a $2000 \mathrm{mg} \mathrm{m}^{-3}$ concentration of $\mathrm{CS}_{2}$ in air as a carrier gas was input at a rate of $0.54 \mathrm{~m}^{3} \mathrm{~h}^{-1}$ in the space between the outer and inner barriers in contact with the tubes containing the packed catalyst. The contact area between the catalyst and the flue gas was increased by fabricating the encasing tube with 6 rows of parallel needlelike pyramids placed inside the inner surface of the encasing tube, as shown in Fig. 1(b).

\section{Analysis of $\mathrm{CS}_{2}$ Treatment}

The performance of the proposed $\mathrm{CS}_{2}$ treatment was evaluated via the decomposition efficiency $\eta$, which is the percentage change in the initial concentration of $\mathrm{CS}_{2}\left(C_{0}\right.$; $\mathrm{mg} \mathrm{m}^{-3}$ ) in the simulated flue gas and the concentration of $\mathrm{CS}_{2}$ in the simulated flue gas after treatment $\left(C_{1} ; \mathrm{mg} \mathrm{m}^{-3}\right)$, and is given as follows:

$$
\eta=\frac{C_{0}-C_{1}}{\mathrm{C}_{0}} \times 100 \%
$$

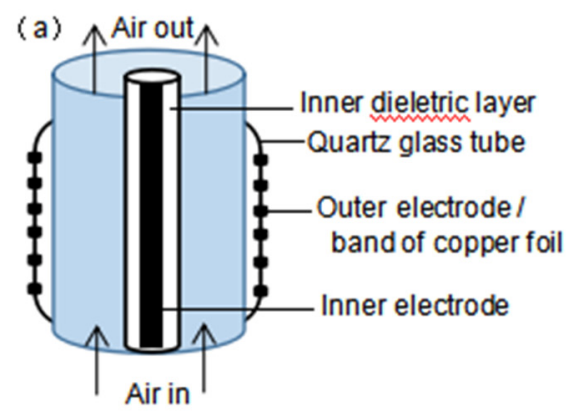

$$
C=\frac{m \cdot v_{1}}{v_{2} \cdot v_{n}}
$$

where $C$ is the concentration of $\mathrm{CS}_{2}$ in the gas to be measured $\left(\mathrm{mg} \mathrm{m}^{-3}\right), m$ is the mass of $\mathrm{CS}_{2}$ dissolved in the sample solution $(\mathrm{mg}), v_{1}$ is the total volume of sample solution $(\mathrm{mL}), v_{2}$ is the volume of sample solution used in analysis $(\mathrm{mL})$, and $v_{n}$ is the volume of the gas sample under standard conditions $\left(\mathrm{m}^{3}\right)$, which refers to the China GBT 14680-1993 standard: Air quality - Determination of carbon disulfide - Diethylamine spectrophotometric method.

\section{Effect of Catalyst Adsorption of CS $\mathrm{CS}_{2}$ on Catalytic Performance}

The value of $C_{1}$ can be decreased without decomposition by the adsorption of $\mathrm{CS}_{2}$ on the catalyst. Therefore, we first conducted control experiments to determine the amount of $\mathrm{CS}_{2}$ adsorbed on the catalyst over time, and thereby evaluate its effect on the overall catalytic performance. To this end, limonite/BiVO 4 (1.2 g, 5:5) and siderite/BiVO 4 (1.2 g, 5:5) composite catalysts calcined at $350^{\circ} \mathrm{C}$ were individually loaded into the reactor, and the values of $C_{1}$ were measured without DBD plasma at different buffer times of 5, 10, 20, 30,40 , and $50 \mathrm{~min}$, and the results compared with $C_{0}$.

\section{Effect of Mass Ratio on the Decomposition Efficiency of $\mathrm{CS}_{2}$}

The values of $\eta$ obtained for the different limonite $/ \mathrm{BiVO}_{4}$ and siderite $/ \mathrm{BiVO}_{4}$ mass ratios of both limonite/ $/ \mathrm{BiVO}_{4}$ and siderite/ $\mathrm{BiVO}_{4}$ were evaluated at the different calcination temperatures. Each catalyst was prepared with five limonite $/ \mathrm{BiVO}_{4}$ or siderite/ $\mathrm{BiVO}_{4}$ mass ratios and four calcination temperatures, for a total of 20 samples, and three replicates of each sample were tested. The DBD plasma power output was controlled by adjusting the DBD voltage between the outer and inner electrodes in the range of $5.0 \mathrm{kV}$ to $9.0 \mathrm{kV}$.

\section{Effect of Calcination Temperature on the Decomposition Efficiency of $\mathrm{CS}_{2}$}

The values of $\eta$ obtained with both the limonite $/ \mathrm{BiVO}_{4}$ and siderite/ $/ \mathrm{BiVO}_{4}$ catalysts calcined at different temperatures were evaluated for limonite/ $/ \mathrm{BiVO}_{4}$ and siderite/BiVO 4 mass ratios of 3:7. The DBD voltage was controlled at $6.0 \mathrm{kV}$.

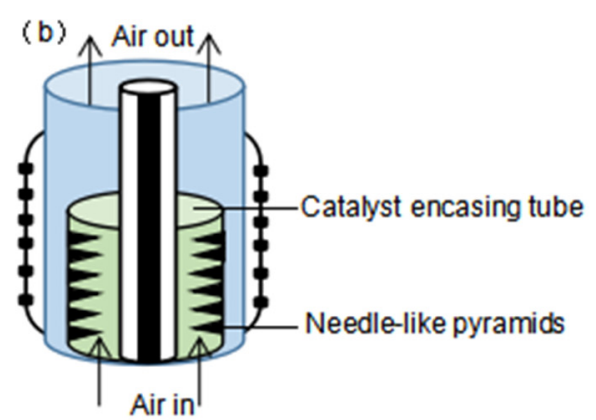

Fig. 1. Schematic diagrams of the dielectric barrier discharge (DBD) plasma reactor setup: (a) cylindrical DBD reactor; (b) catalyst loading structure. 


\section{Analysis of Exhaust Gas}

Qualitative analysis of the tail gas obtained from three $\mathrm{CS}_{2}$ treatment systems: DBD alone, DBD cooperating with limonite/BiVO 4 (mass ratio of 3:7), and DBD cooperating with siderite $/ \mathrm{BiVO}_{4}$ (mass ratio 3:7), was conducted by Fourier transform infrared (FTIR) spectroscopy using a Bruker Vertex 70 spectrometer (Germany). The three $\mathrm{CS}_{2}$ treatment systems were all implemented under the conditions of a $200 \mathrm{mg} \mathrm{m}^{-3} \mathrm{CS}_{2}$ concentration mixed in air, a $0.54 \mathrm{~m}^{3} \mathrm{~h}^{-1}$ intake flow rate, and a DBD voltage adjusted from $5000 \mathrm{~V}$ to $9000 \mathrm{~V}$

Formaldehyde absorption-pararosaniline spectrophotometry (China standard HJ 482-2009) was used to measure the $\mathrm{SO}_{2}$ concentration in the tail gas, and the standard curve was $y=$ $0.0234 x-0.0067$ and $\mathrm{R}^{2}=0.9991$. The concentration of COS was determined indirectly by spectrophotometry, and the standard curve was $y=0.0102 x-0.002$ and $\mathrm{R}^{2}=0.9954$. The concentrations of $\mathrm{CO}$ and $\mathrm{CO}_{2}$ were determined by infrared spectroscopy.

\section{RESULTS AND DISCUSSION}

\section{XRD Analysis}

The XRD patterns of limonite/ $/ \mathrm{BVO}_{4}$ and siderite/BiVO composite catalysts calcined at $350^{\circ} \mathrm{C}$ with different limonite $/ \mathrm{BiVO}{ }_{4}$ and siderite/BiVO 4 mass ratios are shown in Figs. 2(a) and 2(b), respectively. The primary reflections for the limonite/ $\mathrm{BiVO}_{4}$ catalysts in Fig. 2(a) are at $2 \theta$ values of $19.8^{\circ}, 29.2^{\circ}$, and $30.5^{\circ}$. The degree of crystallinity (i.e., the grain size) of a sample can generally be gauged according to the intensity and sharpness (i.e., the full width at half maximum; FWHM) of reflections, where the degree of crystallinity increases with increasing intensity and decreasing FWHM. In contrast, the uniformity of the distribution of crystalline grain constituents in a composite sample increases with increasing FWHM. Analysis of the reflections intensities indicates that the highest intensity reflections with the greater FWHM values were obtained at a limonite/ $\mathrm{BiVO}_{4}$ mass ratio of 3:7, which suggests that the best crystal growth was obtained at this ratio and the $\mathrm{BiVO}_{4}$ was uniformly distributed at the surface of the limonite support (Zhao et al., 2015). The primary reflections for the siderite $/ \mathrm{BiVO}_{4}$ catalysts in Fig. 2(b) are at $2 \theta$ values of $19.4^{\circ}, 29.8^{\circ}$, and $32.6^{\circ}$. The increase in the reflections intensity and FWHM of the XRD reflections obtained at $2 \theta$ values of $19.4^{\circ}, 29.8^{\circ}$, and $32.6^{\circ}$ with increasing $\mathrm{BiVO}_{4}$ content indicates that the $\mathrm{BiVO}_{4}$ is uniformly distributed on the siderite support (Chala et al., 2014).

\section{BET Surface Area, $N_{2}$ Adsorption, and Pore Size}

The $\mathrm{N}_{2}$ adsorption-desorption isotherm diagrams of the limonite $/ \mathrm{BiVO}_{4}$ and siderite $/ \mathrm{BiVO}{ }_{4}$ catalysts calcined at $350{ }^{\circ} \mathrm{C}$ for limonite $/ \mathrm{BiVO}_{4}$ and siderite/BiVO ${ }_{4}$ mass ratios of 3:7 are given in Figs. 3(a) and 3(c), respectively, while the corresponding pore size distributions are presented in Figs. 3(b) and 3(d), respectively. These diagrams are also presented in Fig. 3 for the limonite and siderite support materials. The specific surface areas and pore sizes of the supports and catalysts are listed in Table 1. Figs. 3(a) and 3(c) indicate that all supports and catalysts exhibit type III isotherms with $\mathrm{H} 3$ hysteresis loops, suggesting mesoporous structures with pore diameters in the range of 2-50 nm (Chen et al., 2017b). At low relative pressures, $\mathrm{N}_{2}$ is adsorbed and concentrated on the surface, and capillary condensation occurs within the pores as the relative pressure increases, which yields curves with sharply increasing slopes and hysteresis loops in the diagrams. This indicates that the combination of $\mathrm{BiVO}_{4}$ and limonite or siderite to form composites increased the pore diameter relative to the supports alone. Figs. 3(b) and 3(d) indicate that the pore diameters of the supports and catalysts are between $2.0 \mathrm{~nm}$ and $10 \mathrm{~nm}$, which confirms that these materials have mesoporous structures. As shown in Table 1 , both limonite $/ \mathrm{BiVO}_{4}$ and siderite $/ \mathrm{BiVO}_{4}$ exhibited greater specific surface areas and pore volumes than the corresponding support materials. This indicates that $\mathrm{BiVO}_{4}$ loading altered the pore structure of limonite and siderite, and increased the surface area, and thus increased the concentration of active sites.
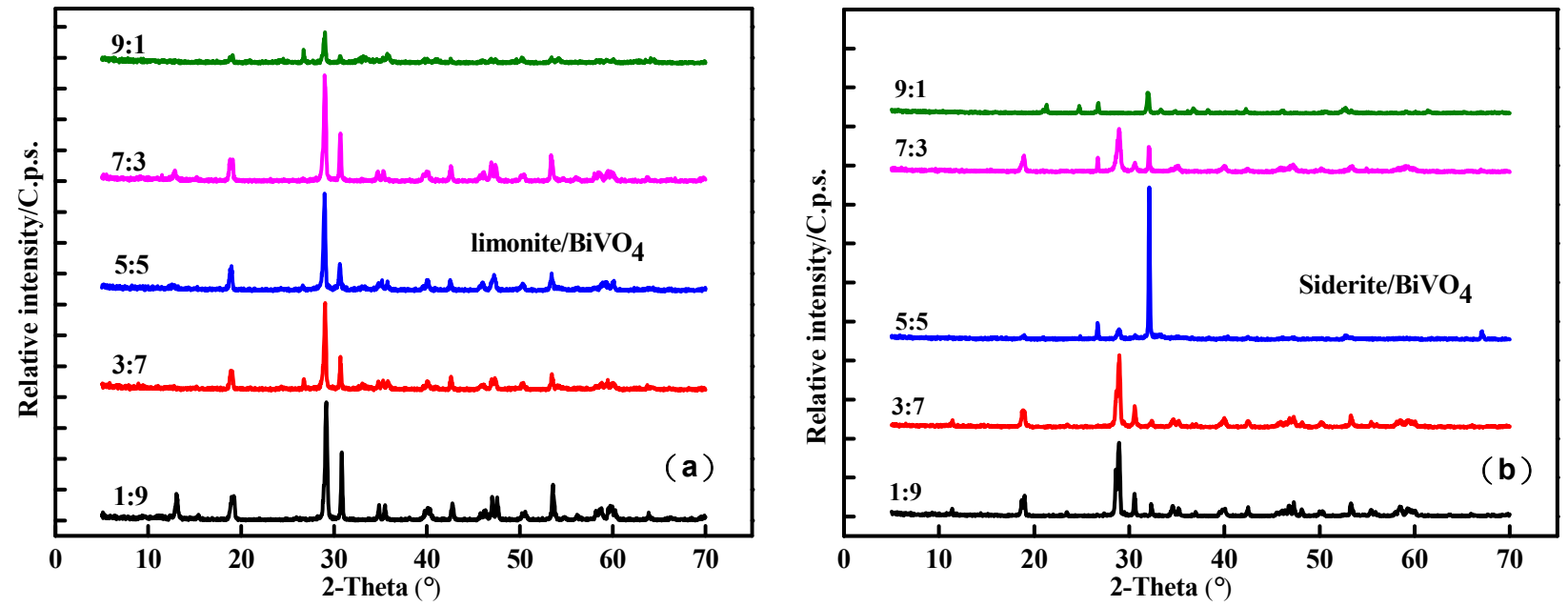

Fig. 2. X-ray diffraction spectra of the composite catalysts calcined at $350^{\circ} \mathrm{C}$ with different limonite/ $\mathrm{BiVO}_{4}$ and siderite $/ \mathrm{BiVO}_{4}$ mass ratios: (a) limonite/BiVO 

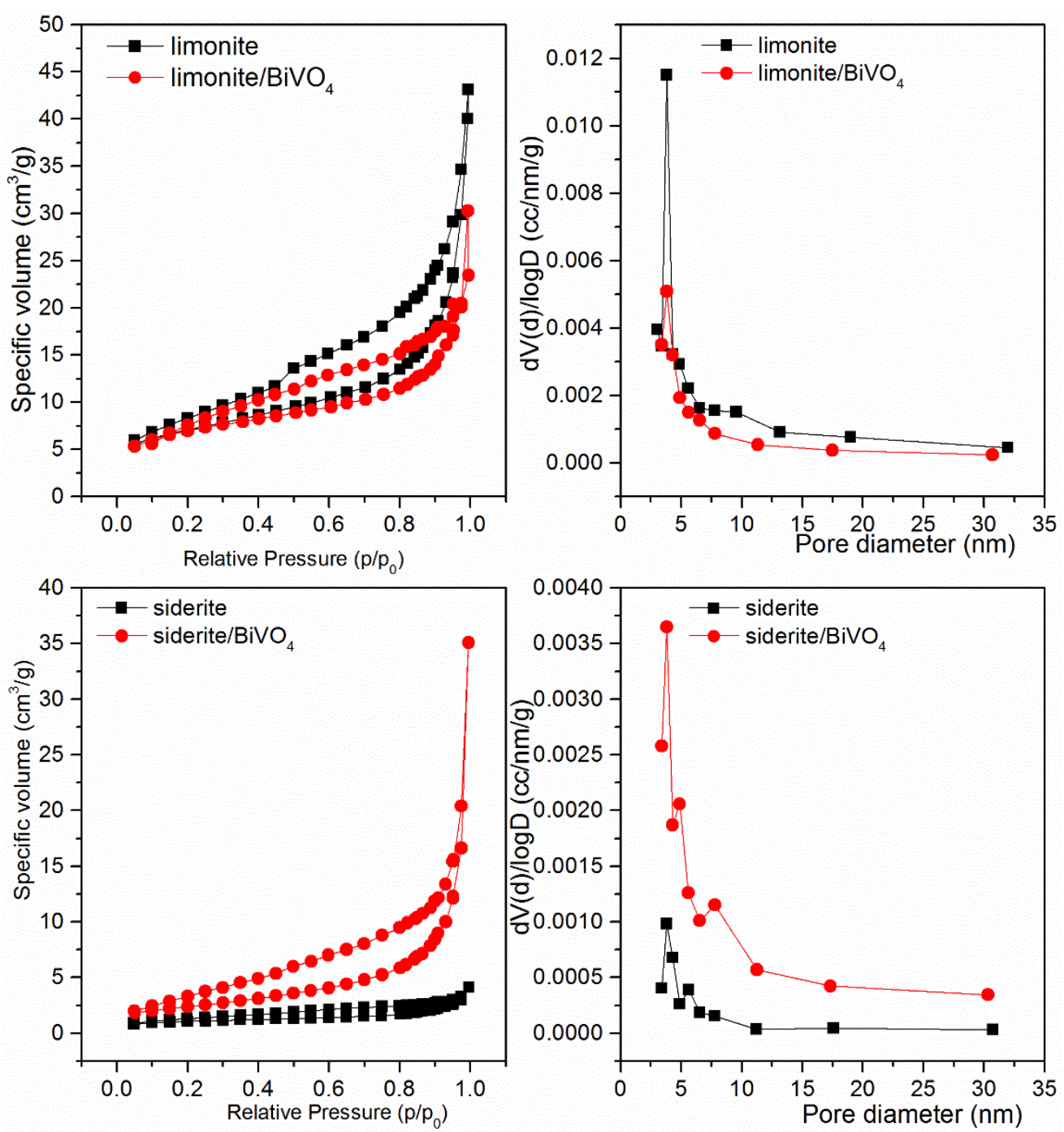

Fig. 3. $\mathrm{N}_{2}$ adsorption-desorption isotherm diagrams (a) and (c), and pore size distributions (b) and (d) of limonite and siderite supports and limonite $/ \mathrm{BiVO}_{4}$ and siderite $/ \mathrm{BiVO} 4$ catalysts calcined at $350{ }^{\circ} \mathrm{C}$ with limonite $/ \mathrm{BiVO}$ and siderite $/ \mathrm{BiVO}_{4}$ mass ratios of 3:7.

Table 1. Specific surface areas and pore sizes of different iron ore supports and composite catalysts with limonite/BiVO4 and siderite/BiVO4 mass ratios of 3:7.

\begin{tabular}{llll}
\hline Sample & Specific surface area $\left(\mathrm{m}^{2} \mathrm{~g}^{-1}\right)$ & Pore volume $\left(\times 10^{-2} \mathrm{~cm}^{3} \mathrm{~g}^{-1}\right)$ & Pore diameter $(\mathrm{nm})$ \\
\hline Limonite & 35.25 & 9.98 & 3.818 \\
Limonite $/ \mathrm{BiVO}_{4}$ & 48.46 & 13.28 & 3.830 \\
Siderite & 3.55 & 0.82 & 3.826 \\
Siderite $/ \mathrm{BiVO}_{4}$ & 10.67 & 2.94 & 3.818 \\
\hline
\end{tabular}

\section{$T G-D T G$}

The differential thermogravimetric (DTG) and thermogravimetric (TG) curves of siderite in a $\mathrm{N}_{2}$ atmosphere are shown in Fig. 4. Four major mass change steps between 30 and $800^{\circ} \mathrm{C}$ are apparent in the TG curve. Combination of the DTG and TG curve data reveals that the mass step changes can be attributed to different reasons. The mass loss occurring between 30 and $277.40^{\circ} \mathrm{C}(1.345 \%)$; as observed in the DTG curve is due to the conversion of goethite into hematite caused by dehydroxylation (Xing et al., 2017). The mass gain occurring between 277.40 and $469.12^{\circ} \mathrm{C}(2.078 \%)$ is due to the oxidation of $\mathrm{FeO}$ to $\mathrm{CO}_{2}$ in $\mathrm{N}_{2}$ prior to the decomposition of the siderite. The mass loss occurring between 469.12 and $673.96^{\circ} \mathrm{C}(14.94 \%)$ is attributed to the conversion of siderite into $\mathrm{Fe}_{3} \mathrm{O}_{4}$, which releases a large amount of $\mathrm{CO}$. Finally, the mass loss between 673.96 and $800^{\circ} \mathrm{C}(1.249 \%)$ is due to the thermal decomposition of residual structural hydroxyl groups. TG analysis indicates that goethite is present in fresh siderite samples. 


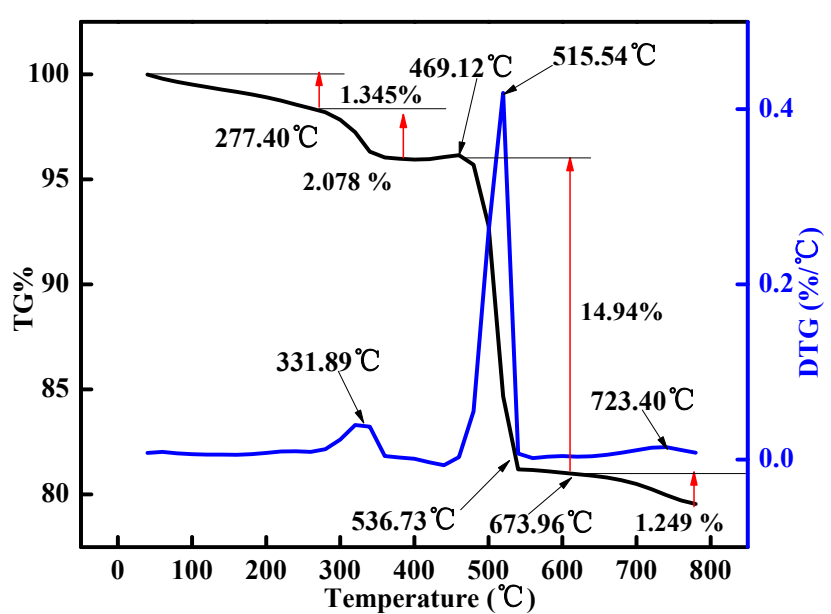

Fig. 4. Thermal gravimetric analysis of siderite.

\section{SEM}

Figs. 5 and 6 respectively present SEM images of limonite $/ \mathrm{BiVO}_{4}$ and siderite $/ \mathrm{BiVO}_{4}$ catalysts calcined at $350^{\circ} \mathrm{C}$ with limonite $/ \mathrm{BiVO}_{4}$ and siderite $/ \mathrm{BiVO}_{4}$ mass ratios of 3:7 (a-c) and 5:5 (d-f). It can be observed from Fig. 5(c) that the limonite surface in the limonite/BiVO 4 catalyst (mass ratio of 3:7) was covered by a smooth layer, and a partially petal shaped morphology is observed, which further suggests that $\mathrm{BiVO}_{4}$ was uniformly distributed on the limonite surface. The SEM images of the limonite/BiVO catalyst (mass ratio of 5:5) exhibit similar morphologies as those observed for the limonite/ $\mathrm{BiVO}_{4}(3: 7)$ catalyst. However, a comparison of Figs. 5(a) and 5(d) suggests that the 3:7 catalyst provides a greater surface area with smoother surfaces and more irregular shapes than the 5:5 catalyst. This may promote interaction between gas precursors and $\mathrm{BiVO}_{4}$ catalysts on iron ore supports. This can be expected to facilitate the interactions of more $\mathrm{BiVO}_{4}$ catalyst loaded to iron ore support (Guan et al., 2010). In addition, comparison of Figs. 5(a) and 5(d) indicates that the 5:5 catalyst presents a different local stacking morphology than the 3:7 catalyst, which suggests the presence of some impurities in the limonite support material. Similar results are observed for the siderite $/ \mathrm{BiVO}_{4}$ catalysts in Fig. 6. Smooth spherical particles are again observed on the siderite surface in Fig. 6(c), suggesting that $\mathrm{BiVO}_{4}$ was uniformly distributed on the siderite surface (Yu et al., 2014). However, aggregations of spherical particles with high intensity detected electron signals are observed in Figs. 6(d) and 6(e), which are indicative of $\mathrm{BiVO}_{4}$ catalyst aggregations at a mass ratio of 5:5. Overall, the SEM images indicate that both limonite/BiVO and siderite $/ \mathrm{BiVO}_{4}$ composite catalysts exhibit better $\mathrm{BiVO}_{4}$ distributions for a mass ratio of 3:7.

\section{XPS}

The XPS survey scan spectra of the limonite and siderite supports calcined at $350^{\circ} \mathrm{C}$ indicate the existence of $\mathrm{O}, \mathrm{Fe}$, and $\mathrm{C}$ elements, while $\mathrm{O}, \mathrm{Fe}, \mathrm{C}, \mathrm{V}$, and $\mathrm{Bi}$ elements were detected in the limonite/ $/ \mathrm{BiO}_{4}$ and siderite $/ \mathrm{BiVO}{ }_{4}$ composite catalysts with mass ratios of $3: 7$ calcined at $350^{\circ} \mathrm{C}$ high

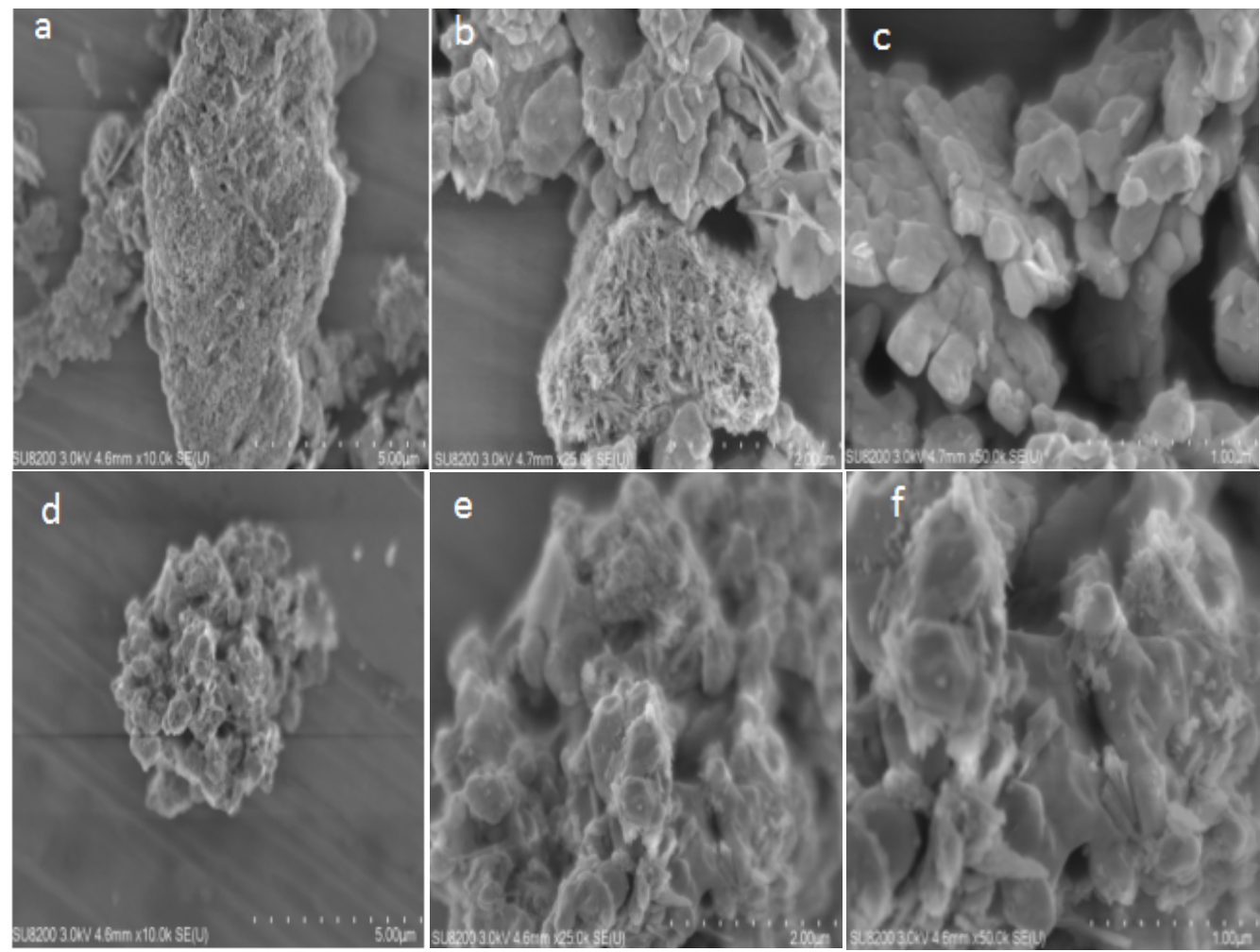

Fig. 5. Scanning electron microscopy images of limonite/ $\mathrm{BiVO}_{4}$ catalysts calcined at $350^{\circ} \mathrm{C}$ for different limonite/BiVO mass ratios: (a), (b), and (c) 3:7 with magnifications of 100000, 250000, and 500000 times, respectively; (d), (e), and (f) 5:5 with magnifications of 100000,250000 , and 500000 times, respectively. 

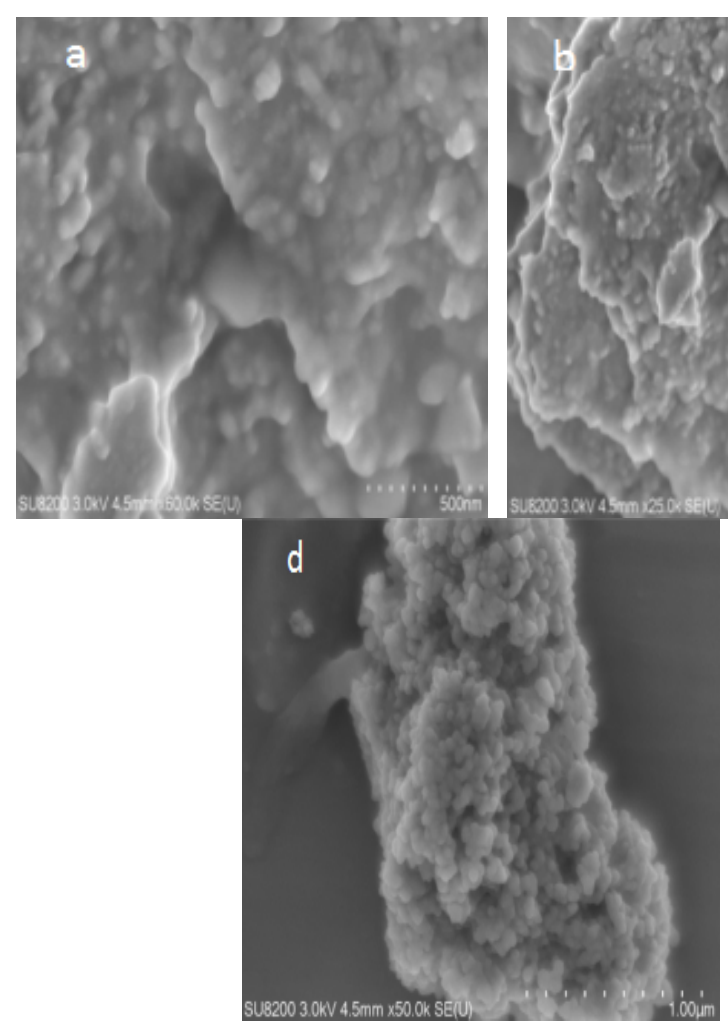

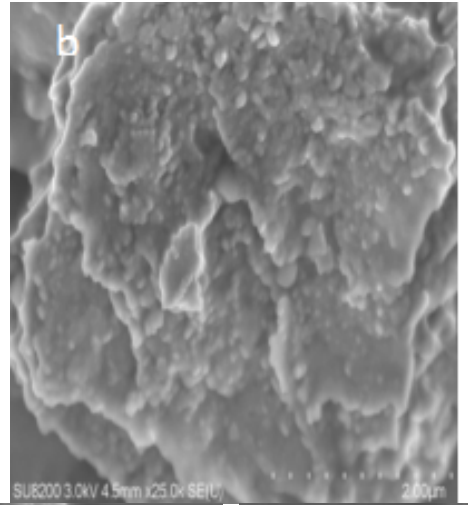

e

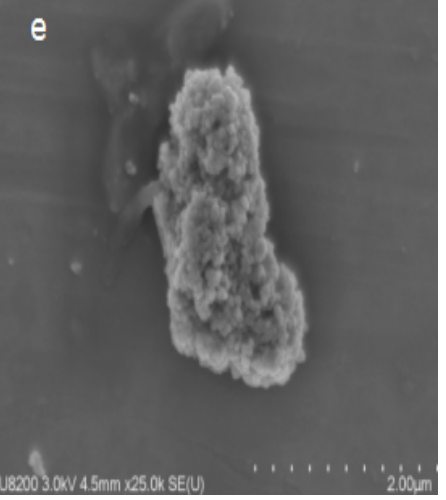

Fig. 6. Scanning electron microscopy images of siderite $/ \mathrm{BiVO}_{4}$ catalysts calcined at $350^{\circ} \mathrm{C}$ for different siderite $/ \mathrm{BiVO} \mathrm{mass}_{4}$ ratios: (a), (b), and (c) 3:7 with magnifications of 100000, 250000, and 500000 times, respectively; (d) and (e) 5:5 with magnifications of 500000 and 250000 times, respectively.

resolution $\mathrm{Fe} 2 \mathrm{p}$ spectra are presented in Fig. 7(a) for limonite $/ \mathrm{BiVO}_{4}$ (top) and limonite (bottom), and the $\mathrm{Bi} 4 \mathrm{f}$ spectrum for limonite/BiVO 4 is presented in Fig. 7(b). The spectra in Fig. 7(a) are fitted, and the binding energies of the $\mathrm{Fe} 2 \mathrm{p} 3 / 2$ and $\mathrm{Fe} 2 \mathrm{p} 1 / 2$ electron states are labeled. Comparison of the fitted $\mathrm{Fe} 2 \mathrm{p}$ spectra of limonite/BiVO 4 and limonite indicates that combining the support with $\mathrm{BiVO}_{4}$ increases the binding energy of $\mathrm{Fe}$, suggesting that the introduction of $\mathrm{BiVO}_{4}$ altered the electron density of the Fe sites (Liu et al., 2017). Similarly, high resolution Fe $2 p$ spectra are presented and fitted in Fig. 6(c) for siderite/ $/ \mathrm{BiVO}_{4}$ (top) and siderite (bottom), and the $\mathrm{Bi} 4 \mathrm{f}$ spectrum for siderite $/ \mathrm{BiVO}_{4}$ is presented and fitted in Fig. 6(d). The two major peaks obtained for the siderite $/ \mathrm{BiVO}_{4}$ catalyst at $708.7 \mathrm{eV}$ and $722.5 \mathrm{eV}$ corresponding to $\mathrm{Fe} 2 \mathrm{p} 3 / 2$ and $\mathrm{Fe} 2 \mathrm{p} 1 / 2$ electron states are consistent with the $\mathrm{Fe}^{3+}$ oxidation state ( $\mathrm{Ji}$ et al., 2015). However, in this case, combining the siderite support with $\mathrm{BiVO}_{4}$ very slightly decreased the binding energies of the Fe 2p3/2 and Fe 2p1/2 electron states. This may lead to a greater electron deficiency and a stronger reduction ability (Yang et al., 2017b). The binding energy of $156.6 \mathrm{eV}$ assigned to the $\mathrm{Bi} 4 \mathrm{f} 5 / 2$ electron state of limonite $/ \mathrm{BiVO}_{4}$ in Fig. 7(b) is consistent with the $\mathrm{Bi}^{3+}$ oxidation state (Kong et al., 2013), while the binding energy of $162 \mathrm{eV}$ assigned to the $\mathrm{Bi} 4 \mathrm{f}$ electron state suggests a higher oxidation state of $\mathrm{Bi}^{5+}$ (Huang et al., 2010). It can be observed that in the high resolution XPS spectrum of limonite/ $\mathrm{BiVO}_{4}$ overlap with some shoulder peaks indicative of varying chemical environments for the $\mathrm{Bi}$ sites (Lamdab et al., 2016). In contrast, the binding energies of the $\mathrm{Bi} 4 \mathrm{f}$ electron states of siderite $/ \mathrm{BiVO}_{4}$ exhibited no overlapping shoulder peaks. The appearance of overlapping shoulder peaks in Fig. 7(b) may be the result of impurities in the naturally occurring limonite. Here, we note that the collected limonite exhibited a lower purity than the siderite, and thus impurity elements may affect the binding energies of the $\mathrm{Bi} 4 \mathrm{f}$ electron states after forming the limonite/BiVO ${ }_{4}$ composite catalysts.

\section{Adsorption Equilibrium of $C_{2}$ Absorbed by Limonite/BiVO ${ }_{4}$ and Siderite/BiVO ${ }_{4}$ Catalysts without DBD}

The $\mathrm{CS}_{2}$ concentration change over time obtained in the $\mathrm{CS}_{2}$ adsorption control experiments are plotted in Fig. S1. These results indicate that the $\mathrm{CS}_{2}$ concentration in reactions involving both the limonite/BiVO 4 and siderite/ $/ \mathrm{BiVO}_{4}$ catalysts reached equilibrium inside the reactor after a buffer time of $30 \mathrm{~min}$. Therefore, all further research conducted in conjunction with plasma discharge was conducted after a 30 min pre-equilibrium period.

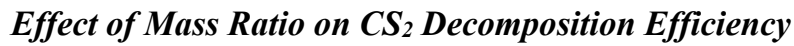

The values of $\eta$ obtained as a function of DBD voltage for DBD plasma treatment alone and for coupled DBD plasma treatment with the limonite $/ \mathrm{BiVO}_{4}$ and siderite $/ \mathrm{BiVO}_{4}$ catalysts calcined at $350{ }^{\circ} \mathrm{C}$ with different limonite $/ \mathrm{BiVO}_{4}$ and siderite $/ \mathrm{BiVO}_{4}$ mass ratios are shown in Figs. 8(a) and $8(\mathrm{~b})$, respectively. The differences between the values of $\eta$ obtained in the coupled and non-coupled treatments were 

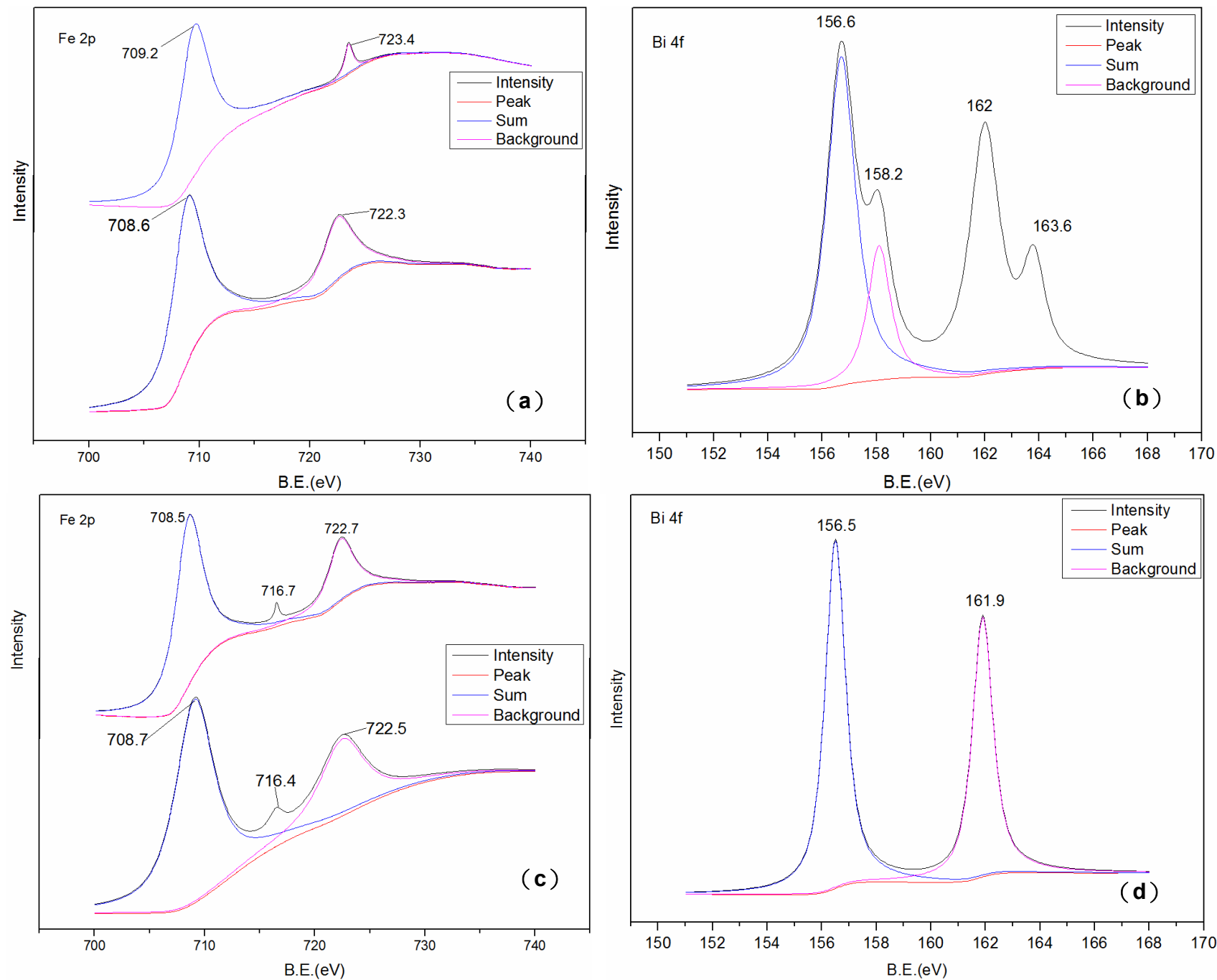

Fig. 7. High resolution Fe $2 p$ spectra of the supports and $\mathrm{Fe} 2 \mathrm{p}$ and $\mathrm{Bi} 4 \mathrm{f}$ spectra of the composite catalysts: (a) Fe $2 p$ spectra for limonite/BiVO 4 (top) and limonite (bottom); (b) $\mathrm{Bi} 4 \mathrm{f}$ spectrum for limonite $/ \mathrm{BiVO}_{4}$; (c) $\mathrm{Fe} 2 \mathrm{p}$ spectra for siderite $/ \mathrm{BiVO}_{4}$ (top) and siderite (bottom); (d) Bi 4f spectrum for siderite/BiVO 4 .

greatest for a DBD voltage of $6.0 \mathrm{kV}$. Compared with DBD plasma treatment alone, the maximum increases in $\eta$ obtained with DBD plasma coupled with the limonite $/ \mathrm{BiVO}_{4}$ catalysts were $8.1 \%, 11.9 \%, 5.6 \%, 5.7 \%$, and $3.7 \%$ for mass ratios of 1:9, 3:7, 5:5, 3:7, and 9:1, respectively. Similarly, the maximum increases in $\eta$ obtained with DBD plasma coupled with the limonite/BiVO 4 catalysts were $8.6 \%$, $13.2 \%, 6.1 \%, 4.4 \%$, and $4.1 \%$ for mass ratios of $1: 9,3: 7$, $5: 5,3: 7$, and $9: 1$, respectively.

We also note from Fig. 8 that value of $\eta$ increased with increasing $\mathrm{BiVO}_{4}$ content up to a maximum at the mass ratio of 3:7, which provided the best value of $\eta$ at any DBD voltage for both limonite/ $\mathrm{BiVO}_{4}$ and siderite $/ \mathrm{BiVO}_{4}$ catalysts, and then decreased for a mass ratio of $9: 1$. This can be explained according to the distribution of the $\mathrm{BiVO}_{4}$ catalyst. An appropriate mass ratio can ensure that $\mathrm{BiVO}_{4}$ is uniformly distributed over the supporting materials (Huang et al., 2015). A low $\mathrm{BiVO}_{4}$ content facilitates the equal distribution of $\mathrm{BiVO}_{4}$ over the available active sites, and more surface becomes covered with an equal distribution of
$\mathrm{BiVO}_{4}$ as the $\mathrm{BiVO}_{4}$ content increases. However, with further increasing $\mathrm{BiVO}_{4}$ content greater than a mass ratio of 3:7, excess $\mathrm{BiVO}_{4}$ is stacked on the surfaces of the support materials, which covers the catalytic active site and decreases the decomposition efficiency (Sriwichai et al., 2014). In addition, the band gaps of the limonite and siderite supports can affect the decomposition efficiency. Here, limonite and siderite possess narrow band gaps, which can facilitate the transfer of electrons and holes from the conduction and valance bands of $\mathrm{BiVO}_{4}$, and thereby inhibit the annihilation of electron-hole pairs within $\mathrm{BiVO}_{4}$ (Wang et al., 2016; Wang et al., 2017; Xia et al., 2017).

The results in Fig. 8 can be included with the results shown in Figs. S2 and S3 to compare the values of $\eta$ obtained as a function of DBD voltage for DBD plasma treatment alone and for coupled DBD plasma treatment with the limonite $/ \mathrm{BiVO}_{4}$ and siderite $/ \mathrm{BiVO}_{4}$ catalysts with different mass ratios under calcination temperatures of $250^{\circ} \mathrm{C}, 350^{\circ} \mathrm{C}$ (Fig. 7), $450^{\circ} \mathrm{C}$, and $550^{\circ} \mathrm{C}$. We note that the variations in $\eta$ with respect to the DBD voltage for the 

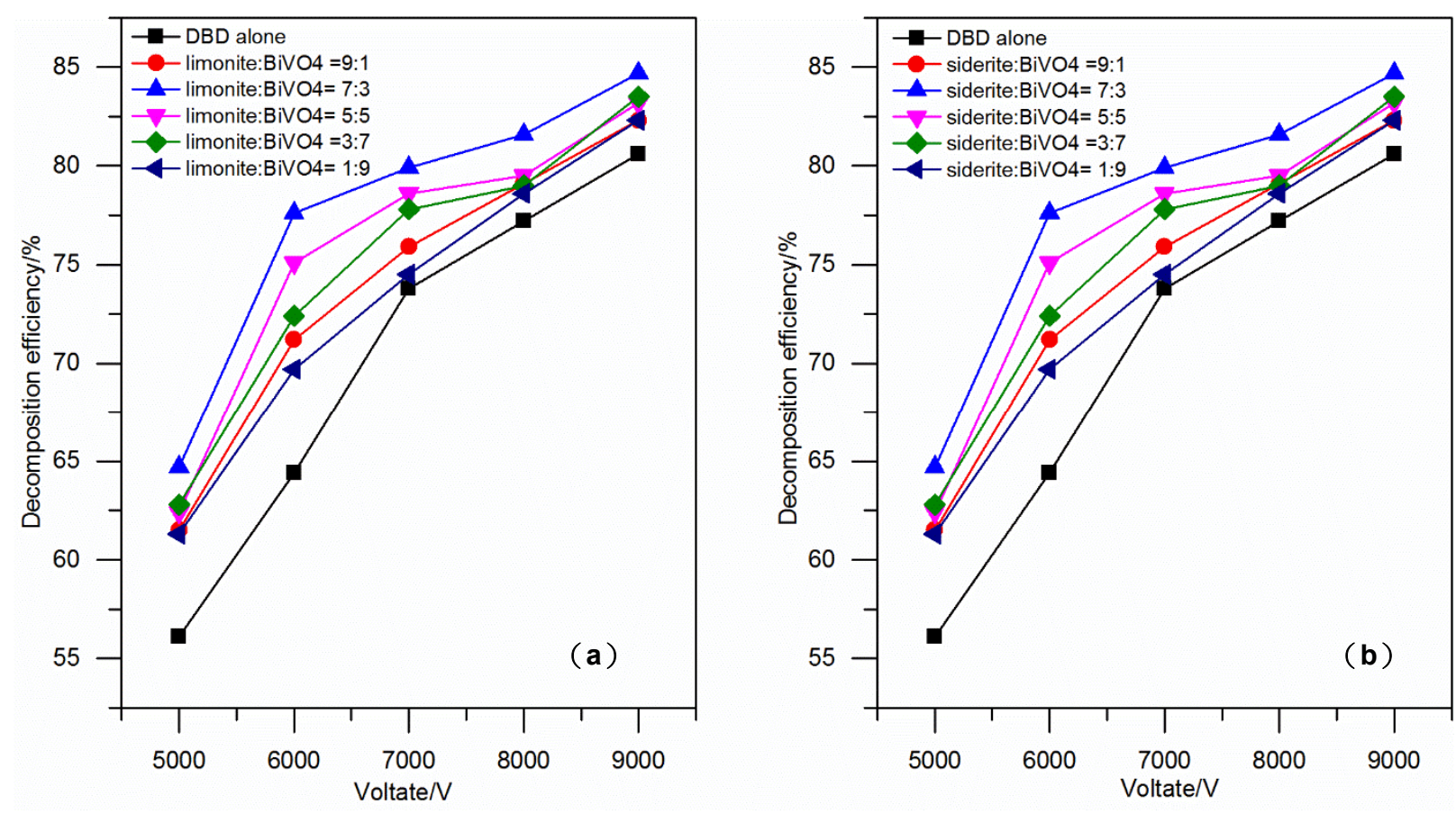

Fig. 8. $\mathrm{CS}_{2}$ decomposition efficiency $(\eta)$ for catalysts calcined at $350^{\circ} \mathrm{C}$ with different limonite $/ \mathrm{BiVO} \mathrm{O}_{4}$ and siderite/BiVO mass ratios: (a) limonite/ $\mathrm{BiVO}$; (b) siderite/ $/ \mathrm{BiVO}_{4}$.

different calcination temperatures represent similar trends as those obtained at $350^{\circ} \mathrm{C}$ in Fig. 7.

\section{Effect of Calcination Temperature on $\mathrm{CS}_{2}$ Decomposition Efficiency}

Fig. 9 present the increases in the values of $\eta$ compared with DBD treatment alone obtained for coupled DBD plasma treatment at a DBD voltage of $6.0 \mathrm{kV}$ using the limonite $/ \mathrm{BiVO}_{4}$ and siderite $/ \mathrm{BiVO}_{4}$ catalysts with a mass ratio of 3:7 under different calcination temperatures. Here, we note that the increases in the values of $\eta$ first increased with increasing calcination temperature, and then decreased after reaching peak performance at $350^{\circ} \mathrm{C}$ for both catalysts. This trend can be related to changes in the crystal structure of the catalysts at different calcination temperatures. The optimal calcination temperature of $\mathrm{BiVO}_{4}$ lies between $300^{\circ} \mathrm{C}$ and $400^{\circ} \mathrm{C}$, although the higher temperature in this range can lead to changes in the crystal morphology (Zhao et al., 2012; Yuan et al., 2015; Xia et al., 2017). The limonite and siderite support materials, as well as the composites, also suffer from disadvantageous changes in the surface area and pore size under higher calcination temperatures owing to pore space collapse and $\mathrm{BiVO}_{4}$ catalyst aggregation, resulting in decreased catalytic performance (Liu and Zhou, 2015).

\section{Comparison of CS Treatment Involving Limonite and Siderite Supports}

The values of $\eta$ obtained as a function of DBD voltage in Fig. 8 for DBD plasma treatment alone and for coupled DBD plasma treatment with the limonite $/ \mathrm{BiVO}_{4}$ and siderite $/ \mathrm{BiVO}_{4}$ catalysts calcined at $350^{\circ} \mathrm{C}$ with a mass ratio of $3: 7$ are presented in Fig. S4 to facilitate detailed comparison. Compared with DBD plasma treatment alone at a DBD voltage of $6.0 \mathrm{kV}$, coupled DBD plasma treatment with the siderite $/ \mathrm{BiVO}_{4}$ catalyst increased the value of $\eta$ by $13.2 \%$, while coupled DBD plasma treatment with the limonite $/ \mathrm{BiVO}_{4}$ catalyst increased the value of $\eta$ by $11.9 \%$. This small difference could be due to the structural and compositional differences between limonite and siderite. The results of additional experiments being conducted presently to study the effect of catalyst structure and composition on $\mathrm{CS}_{2}$ decomposition performance will be reported in the future.

\section{Analysis of Exhaust Gas}

The exhaust gas FTIR spectrum is shown in Fig. 10. Here, the peak at $1373 \mathrm{~cm}^{-1}$ represents $\mathrm{S}=\mathrm{O}$ bond stretching vibrations (Rudakova et al., 2003), indicating that the substance is $\mathrm{SO}_{2}$, the peak at $2345 \mathrm{~cm}^{-1}$ represents $\mathrm{C}=\mathrm{O}$ bond stretching vibrations, indicating that the substance is $\mathrm{CO}_{2}$, the peak at $2100 \mathrm{~cm}^{-1}$ represents $\mathrm{C}$ and $\mathrm{O}$ triple bond stretching vibrations ( Chen et al., 2007), indicating that the substance is $\mathrm{CO}$, the peak near $2084 \mathrm{~cm}^{-1}$ represents stretching vibrations for the $\mathrm{C}=\mathrm{O}$ bond of $\mathrm{COS}$ (Yan et al., 2013), and the peak at $1015 \mathrm{~cm}^{-1}$ is an $\mathrm{O}_{3}$ absorption peak, indicating that the intermediate products of $\mathrm{CS}_{2}$ degradation are $\mathrm{SO}_{2}, \mathrm{CO}, \mathrm{CO}_{2}$, and $\mathrm{COS}$.

Fig. 11 shows that the concentrations of $\mathrm{SO}_{2}, \mathrm{CO}, \mathrm{CO}_{2}$, and $\mathrm{COS}$ in the exhaust gas for all treatments increase with increasing DBD voltage. Here, $\mathrm{CS}_{2}$ receives energy in the process of reactor discharge, and is stimulated to produce intermediate products, such as $\mathrm{CS}^{*}$, active group $\mathrm{O}_{3}^{-}, \mathrm{OH}^{-}$, and $\mathrm{O}_{3}$. These intermediate products can then form additional products, where $\mathrm{CS}^{*}$ and $\mathrm{O}_{2}$ can produce $\mathrm{SO}_{2}, \mathrm{~S}$ and $\mathrm{O}_{2}$ can produce $\mathrm{SO}$ and then react with $\mathrm{O}_{2}$ to produce $\mathrm{SO}_{2}, \mathrm{CS}$ and $\mathrm{O}_{2}$ can produce $\mathrm{COS}$ and $\mathrm{O}$, and $\mathrm{O}$ reacts with $\mathrm{SO}_{2}$ to 


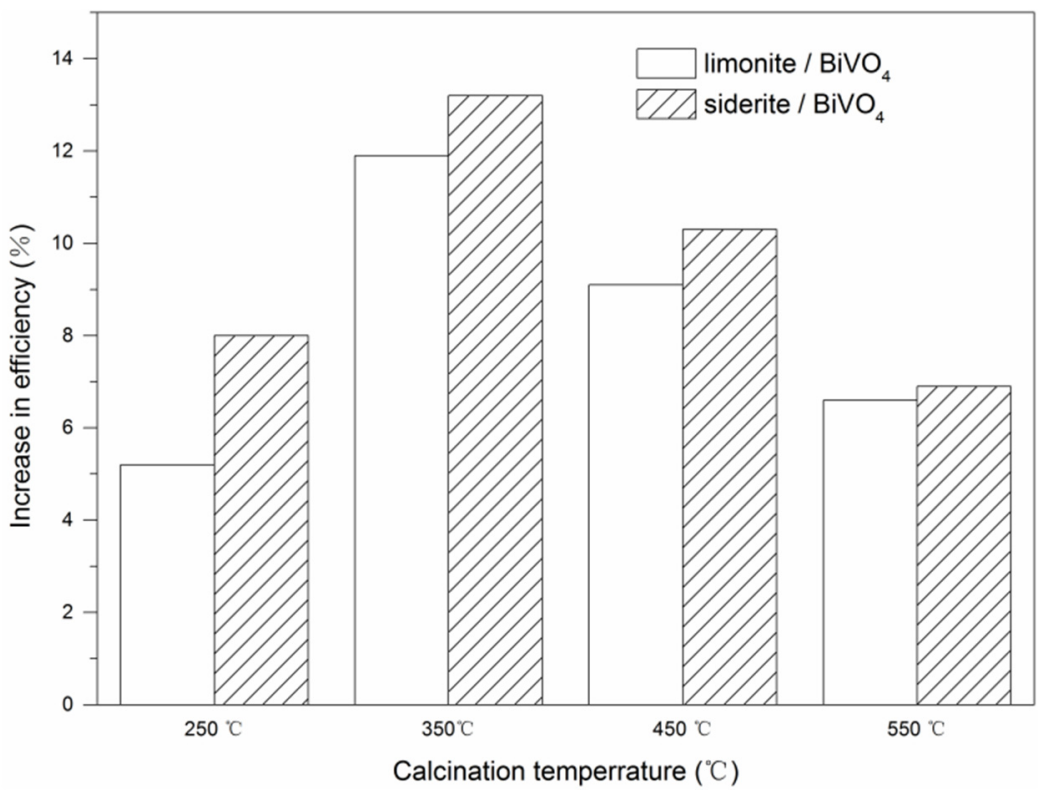

Fig. 9. Values of $\eta$ for catalysts with limonite $/ \mathrm{BiVO}_{4}$ and siderite/ $\mathrm{BiVO}_{4}$ mass ratios of 3:7 obtained under different calcination temperatures.

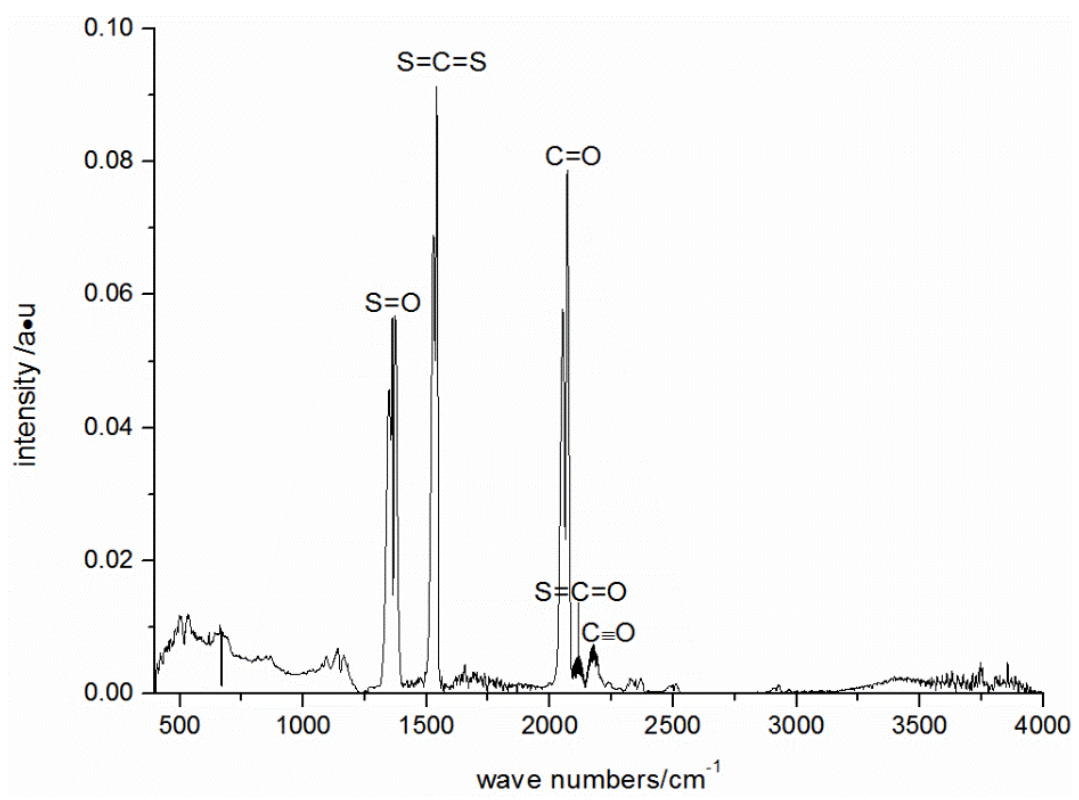

Fig. 10. Fourier transform infrared spectrum of exhaust gas.

produce $\mathrm{CO}$ and $\mathrm{CO}_{2}$. An increasing concentration of $\mathrm{CS}$ and active groups $\mathrm{O}, \mathrm{O}_{2}$, and $\mathrm{O}_{3}$ are generated with increasing DBD voltage, resulting in the production of increased concentrations of $\mathrm{SO}_{2}, \mathrm{COS}$, and carbon oxides. The concentrations of $\mathrm{SO}_{2}, \mathrm{CO}$, and $\mathrm{COS}$ in the tail gas of the DBD combined with catalyst treatments are less than those obtained by DBD treatment alone, but the concentration of $\mathrm{CO}_{2}$ is greater than that obtained by DBD treatment alone. Under a DBD voltage of $9000 \mathrm{~V}$, the concentrations of $\mathrm{SO}_{2}$, $\mathrm{CO}, \mathrm{COS}$, and $\mathrm{CO}_{2}$ in the tail gas obtained for DBD treatment alone were $121.4 \mathrm{mg} \mathrm{m}^{-3}, 106.3 \mathrm{mg} \mathrm{m}^{-3}, 62.7 \mathrm{mg} \mathrm{m}^{-3}$, and $80.5 \mathrm{mg} \mathrm{m}^{-3}$, respectively, while these were $104.7 \mathrm{mg} \mathrm{m}^{-3}$, $89.0 \mathrm{mg} \mathrm{m}^{-3}, 56.1 \mathrm{mg} \mathrm{m}^{-3}, 100.9 \mathrm{mg} \mathrm{m}^{-3}$, respectively, under the DBD cooperating with limonite/BiVO 4 (mass ratio $3: 7$ ) treatment, and $87.1 \mathrm{mg} \mathrm{m}^{-3}, 81.9 \mathrm{mg} \mathrm{m}^{-3}, 49.6 \mathrm{mg} \mathrm{m}^{-3}$, and $103.6 \mathrm{mg} \mathrm{m}^{-3}$, respectively, under the DBD cooperating with siderite $/ \mathrm{BiVO}_{4}$ (mass ratio of $3: 7$ ) treatment. Therefore, compared with DBD cooperating with limonite/BiVO, DBD cooperating with siderite $/ \mathrm{BiVO}_{4}$ produced a greater concentration of $\mathrm{CO}_{2}$, and smaller concentrations of $\mathrm{SO}_{2}$, $\mathrm{CO}$, and COS.

\section{Comparison with Other CS Treatments}

Compared with a previously reported coupled DBD plasma $\mathrm{MnO}_{2}$ catalytic $\mathrm{CS}_{2}$ treatment system, the proposed coupled DBD $\mathrm{CS}_{2}$ treatment system employing limonite/BiVO 4 and 

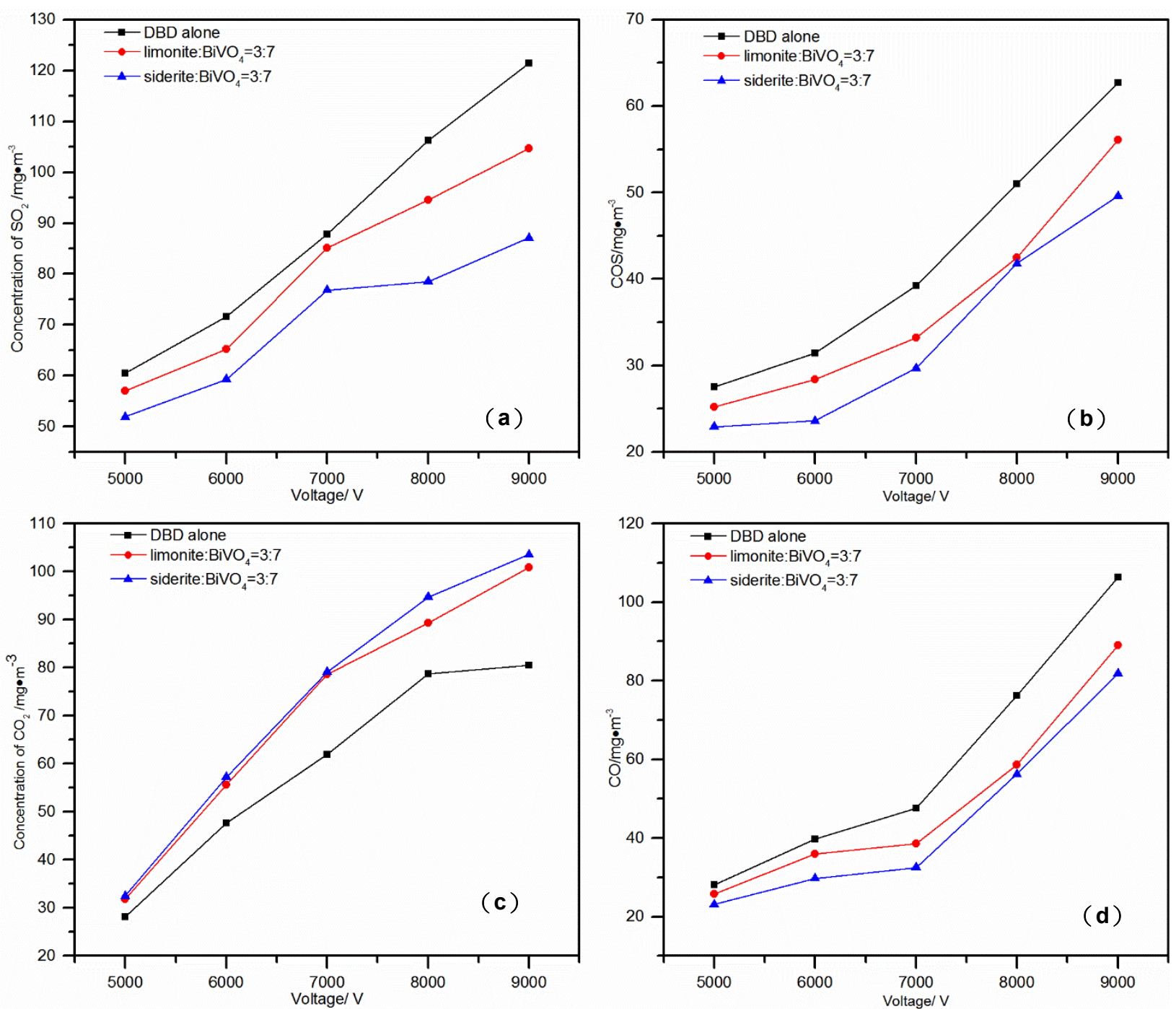

Fig. 11. Changes in $\mathrm{SO}_{2}, \mathrm{COS}, \mathrm{CO}_{2}$, and $\mathrm{CO}$ concentrations in the tail gas under different $\mathrm{DBD}$ voltage treatments: (a) $\mathrm{SO}_{2}$; (b) $\mathrm{COS}$; (c) $\mathrm{CO}_{2}$; (d) $\mathrm{CO}$.

siderite $/ \mathrm{BiVO}_{4}$ catalysts calcined at $350^{\circ} \mathrm{C}$ with a mass ratio of 3:7 exhibited $\eta$ values that were around $5 \%$ greater under equivalent reaction conditions. This could due to the close energy band interactions of the $\mathrm{BiVO}_{4}$ photocatalyst with the supporting iron ore materials that prolonged the lifetime of the activated oxygen species by inhibiting the annihilation of electron-hole pairs within $\mathrm{BiVO}_{4}$. The $\mathrm{CS}_{2}$ decomposition efficiency is also enhanced relative to that of the $\mathrm{MnO}_{2}$ catalytic system by the high surface area and better porous structure of the supporting materials, which facilitates the equal distribution of catalytic active sites.

\section{CONCLUSIONS}

This study developed an efficient $\mathrm{CS}_{2}$ decomposition method based on DBD plasma coupled with a novel $\mathrm{BiVO}_{4}$ photocatalyst supported by a limonite $(\mathrm{FeO}(\mathrm{OH}))$ or siderite $\left(\mathrm{FeCO}_{3}\right)$ iron ore material. The catalyst was synthesized via a hydrothermal method. The effects of the limonite/BiVO and siderite $/ \mathrm{BiVO}_{4}$ mass ratios and calcination temperature on the $\mathrm{CS}_{2}$ decomposition efficiency of DBD plasma coupled with the limonite/BiVO 4 and siderite $/ \mathrm{BiVO}{ }_{4}$ composite catalysts were experimentally investigated using a standard DBD plasma reactor. The optimum composition for both composite catalysts was obtained at a calcination temperature of $350^{\circ} \mathrm{C}$ with limonite $/ \mathrm{BiVO}_{4}$ and siderite $/ \mathrm{BiVO}_{4}$ mass ratios of 3:7. The results of DBD plasma coupled with the optimum limonite/BiVO 4 and siderite/ $/ \mathrm{BiVO}_{4}$ composite catalysts demonstrated increased $\mathrm{CS}_{2}$ decomposition efficiencies of $11.9 \%$ and $13.2 \%$, respectively, relative to that of DBD plasma alone. The slightly better performance of the siderite/ $\mathrm{BiVO}_{4}$ composite catalyst than limonite/BiVO could be due to the composition of the limonite and siderite iron ores. The main components of the tail gas after DBD synergistic catalytic treatment of $\mathrm{CS}_{2}$ were $\mathrm{SO}_{2}, \mathrm{COS}, \mathrm{CO}$, and $\mathrm{CO}_{2}$. The catalyst can increase the oxidizing species of the discharge system, and ensure the more thorough oxidation of $\mathrm{SO}_{2}$ and $\mathrm{COS}$, resulting in smaller concentrations of $\mathrm{SO}_{2}$, $\mathrm{COS}$, and $\mathrm{CO}$, and greater concentrations of $\mathrm{CO}_{2}$ in the tail gas. Future study will focus on how minor elements and the 
morphology of the supporting materials affect the $\mathrm{CS}_{2}$ decomposition efficiency of the composite catalysts.

\section{ACKNOWLEDGMENTS}

The authors acknowledge the financial support obtained from Anhui Province's 2018 Annual Key Research and Development Plan Project (Grant No. 1804a09020096), Hefei Municipal Independent Innovation Policy "Borrowing Subsidy" Fund Project in 2018 (Grant No. J2018G27), Research and Development Fund Project of Hefei University (Grant No. 18ZR03ZDA), the Natural Science Research Projects of the Anhui Higher Education Institutions of China in 2019 (Grant No. KJ2019A0827).

\section{SUPPLEMENTARY MATERIAL}

Supplementary data associated with this article can be found in the online version at http://www.aaqr.org.

\section{DISCLAIMER}

The authors declare no competing financial interest.

\section{REFERENCES}

Albertos, I., Martín-Diana, A.B., Cullen, P.J, Tiwari, B.K., Ojha, SK., Bourke, P., Álvarez, C. Rico, D. and Technologies, E. (2017). Effects of dielectric barrier discharge (DBD) generated plasma on microbial reduction and quality parameters of fresh mackerel (Scomber scombrus) fillets. Innovative Food Sci. Emerg. Technol. 44: 117-122.

Bates, T.S., Lamb, B.K., Guenther, A., Dignon, J. and Stoiber, RE. (1992). Sulfur emissions to the atmosphere from natural sourees. J. Atmos. Chem. 14: 315-337.

Chala, S., Wetchakun, K., Phanichphant, S., Inceesungvorn, B. and Wetchakun, N. (2014). Enhanced visible-lightresponse photocatalytic degradation of methylene blue on Fe-loaded $\mathrm{BiVO}_{4}$ photocatalyst. J. Alloys Compd. 597: 129-135.

Chen, F., Yang, Q., Li, X., Zeng, G., Wang, D., Niu, C., Zhao, J., An, H., Xie, T. and Deng, Y. (2017b). Hierarchical assembly of graphene-bridged $\mathrm{Ag}_{3} \mathrm{PO}_{4} / \mathrm{Ag} / \mathrm{BiVO}_{4}(040)$ Z-scheme photocatalyst: An efficient, sustainable and heterogeneous catalyst with enhanced visible-light photoactivity towards tetracycline degradation under visible light irradiation. Appl. Catal. 200: 330-342.

Chen, H., Kong, L., Chen, J., Zhang, R. and Wang, L. (2007). Heterogeneous uptake of carbonyl sulfide on hematite and hematite- $\mathrm{NaCl}$ mixtures. Environ. Sci. Technol. 41: 6484-6490.

Chen, R., Zhu, C., Lu, J., Xiao, J., Lei, Y. and Yu, Z. (2018). $\mathrm{BiVO}_{4} / \alpha-\mathrm{Fe}_{2} \mathrm{O}_{3}$ catalytic degradation of gaseous benzene: Preparation, characterization and photocatalytic properties. Appl. Surf. Sci. 427: 141-147.

Chen, Y., Wang, M., Du, X., Ran, J., Zhang, L. and Tang, D. (2017a). High Resistance to Na Poisoning of the $\mathrm{V}_{2} \mathrm{O}_{5}$ $\mathrm{Ce}\left(\mathrm{SO}_{4}\right)_{2} / \mathrm{TiO}_{2}$ Catalyst for the NO SCR Reaction.
Aerosol Air Qual. Res. 12: 2948-2955.

Cheng, S.W., Li, Y.H, Yuan, C.S., Tsai, P.Y., Shen, H.Z. and Hung, C.H. (2018). An innovative advanced oxidation technology for effective decomposition of formaldehyde by combining iron modified nano- $\mathrm{TiO}_{2} \quad\left(\mathrm{Fe} / \mathrm{TiO}_{2}\right)$ photocatalytic degradation with ozone oxidation. Aerosol Air Qual. Res. 12: 3220-3233.

Futamura, S. (2005). VOCs removal with nonthermal plasma and catalysts. J. Jpn. Inst. Energy 84: 474-479.

Guan, M.L., Ma, D.K., Hu, S.W., Chen, Y.J. and Huang, S.M. (2010). From hollow olive-shaped $\mathrm{BiVO}_{4}$ to n-p core-shell $\mathrm{BiVO}_{4} @ \mathrm{Bi}_{2} \mathrm{O}_{3}$ microspheres: Controlled synthesis and enhanced visible-light-responsive photocatalytic properties. Inorg. Chem. 50: 800-805.

Holzer, F., Roland, U. and Kopinke, F.D. (2002). Combination of non-thermal plasma and heterogeneous catalysis for oxidation of volatile organic compounds: Part 1. Accessibility of the intra-particle volume. Appl. Catal. B 38: 163-181.

Huang, C.M., Pan, G.T., Peng, P.Y. and Yang, T.C. (2010). In situ DRIFT study of photocatalytic degradation of gaseous isopropanol over $\mathrm{BiVO}_{4}$ under indoor illumination. J. Mol. Catal. A 327: 38-44.

Huang, H., Liu, L., Zhang, Y. and Tian, N. (2015). Novel $\mathrm{BiIO}_{4} / \mathrm{BiVO}_{4}$ composite photocatalyst with highly improved visible-light-induced photocatalytic performance for rhodamine B degradation and photocurrent generation. RSC Adv. 5: 1161-1167.

Huang, Y., Cao, J.J., Kang, F., You, S.J., Chang, C.W. and Wang, Y.F. (2017). High selectivity of visible-lightdriven La-doped $\mathrm{TiO}_{2}$ photocatalysts for NO Reoval. Aerosol Air Qual. Res. 10: 2555-2565.

Ji, K., Dai, H., Deng, J., Zang, H., Arandiyan, H., Xie, S. and Yang, H. (2015). 3DOM BiVO 4 supported silver bromide and noble metals: High-performance photocatalysts for the visible-light-driven degradation of 4-chlorophenol. Appl. Catal. B 168: 274-282.

Jia, J., Cheng, S., Liu, L., Lang, J., Wang, G., Chen, G. and Liu, X. (2017). An integrated WRF-CAMx Modeling approach for impact analysis of implementing the emergency $\mathrm{PM}_{2.5}$ control measures during red alerts in Beijing in December 2015. Aerosol Air Qual. Res. 10: 2491-2508.

Kirkpatrick, M. J., Odic, E., Zinola, S. and Lavy, J. (2012). Plasma assisted heterogeneous catalytic oxidation: HCCI diesel engine investigations. Appl. Catal. B 117: 1-9.

Kong, L., Jiang, Z., Lai, H.C., Xiao, T and Edwards, P.P. (2013). Does noble metal modification improve the photocatalytic activity of BiOCl? Prog. Nat. Sci. 23: 286293.

Krawczyk, K. and Mlotek, M. (2001). Combined plasmacatalytic processing of nitrous oxide. Appl. Catal. B 30: 233-245.

Laing, J., Jaffe, D.A., Slavens, A.P., Li, W. and Wang, W. (2017). Can $\Delta \mathrm{PM}_{2.5} / \Delta \mathrm{CO}$ and $\Delta \mathrm{NO}_{\mathrm{y}} / \Delta \mathrm{CO}$ enhancement ratios be used to characterize the influence of wildfire smoke in urban areas. Aerosol Air Qual. Res. 10: 24132423.

Lamdab, U., Wetchakun, K., Phanichphant, S., 
Kangwansupamonkon, W. and Wetchakun, N. (2016). $\mathrm{InVO}_{4}-\mathrm{BiVO}_{4}$ composite films with enhanced visible light performance for photodegradation of methylene blue. Catal. Today 278: 291-302.

Li, J., Zhao, W., Guo, Y., Wei, Z., Han, M., He, H., Yang, S. and Sun, C. (2015) Facile synthesis and high activity of novel $\mathrm{BiVO}_{4} / \mathrm{FeVO}_{4}$ heterojunction photocatalyst for degradation of metronidazole. Appl. Surf. Sci. 351: 270279.

Li, Q., Liu, H., Chen, T., Chen, D., Zhang, C., Xu, B., Zhu C. and Jiang, Y. (2017a). Characterization and SCR performance of nano-structured iron-manganese oxides: Effect of annealing temperature. Aerosol Air Qual. Res. 17: 2328-2337.

Li, Y., Yang, L., Chen, X., Gao, Y., Jiang, Pan., Zhang, J., $\mathrm{Yu}, \mathrm{H}$. and Wang, W. (2017b). $\mathrm{PM}_{2.5}$-bound PAHs in indoor and outdoor of hotels in urban and suburban of Jinan, China: Concentrations, sources, and health risk impacts. Aerosol Air Qual. Res. 10: 2463-2473.

Liang, H., Chen, W., Wang, R., Qi, Z., Mi, J. and Wang, Z. (2015). X-shaped hollow $\alpha-\mathrm{FeOOH}$ penetration twins and their conversion to $\alpha-\mathrm{Fe}_{2} \mathrm{O}_{3}$ nanocrystals bound by high-index facets with enhanced photocatalytic activity. Chem. Eng. J. 274: 224-230.

Liu, H.X. and Liu, Y. (2011). Removal of P-Xylene by a DBD-type plasma combined with catalyst. Environ. Eng. Manage. 10: 749-753.

Liu, S., Tang, H., Zhou, H., Dai, G. and Wang, W. (2017). Photocatalytic perfermance of sandwich-like $\mathrm{BiVO}_{4}$ sheets by microwave assisted synthesis. Appl. Surf. Sci. 391: 542-547.

Liu, Y., Yin, Y., Jia, X., Cui, X., Tian, C., Sang, Y. and Liu, H. (2016). Synthesis process and photocatalytic properties of $\mathrm{BiOBr}$ nanosheets for gaseous benzene. Environ. Sci. Pollut. Res. 23: 17525-17531.

Liu, Z. and Zhou, C. (2015). Improved photocatalytic activity of nano $\mathrm{CuO}$-incorporated $\mathrm{TiO}_{2}$ granules prepared by spray drying. Prog. Nat. Sci. 25: 334-341.

Pham, T.D., Lee, B.K. and Lee, C.H. (2016). The advanced removal of benzene from aerosols by photocatalytic oxidation and adsorption of $\mathrm{Cu}-\mathrm{TiO}_{2} / \mathrm{PU}$ under visible light irradiation. Appl. Catal. B. 182: 172-183.

Price, B., Bergman, T.S., Rodríguez, M., Henrich, R.T. and Moran, E.J. (1997). A review of carbon disulfide exposure data and the association between carbon disulfide exposure and ischemic heart disease mortality. Regul. Toxicol. Pharm. 26: 119-128.

Rojo, N., Gallastegui, G., Barona, A., Gurtubay, L., IbarraBerastegi, G. and Elías, A. (2010). Biotechnology as an alternative for carbon disulfide treatment in air pollution control. Environ. Rev. 18: 321-332.

Rudakova, A.V., Lobo, R.F. and Bulanin, K.M. (2003). FTIR study of carbon monoxide adsorption on Li-exchanged zeolite X. J. Phys. Chem. 107: 5212-5220.

Singh, P., Ojha, A., Borthakur, A., Singh, R., Lahiry, D., Tiwary, D. and Mishra, P.K. (2016). Emerging trends in photodegradation of petrochemical wastes: A review. Environ. Sci. Pollut. Res. 23: 22340-22364.

Sriwichai, S., Ranwongsa, H., Wetchakun, K., Phanichphant,
S. andWetchakun, N. (2014). Microstructures. Effect of iron loading on the photocatalytic performance of $\mathrm{Bi}_{2} \mathrm{WO}_{6}$ photocatalyst. Superlattices Microstruct. 76: 362-375.

Tabari, T., Singh, D. and Jamali, S.S. (2017). Enhanced photocatalytic activity of mesoporous $\mathrm{ZnFe}_{2} \mathrm{O}_{4}$ nanoparticles towards gaseous benzene under visible light irradiation. J. Environ. Chem. Eng. 5: 931-939.

Vandenbroucke, A.M., Morent, R., Geyter, N.D. and Leys, C. (2011). Non-thermal plasmas for non-catalytic and catalytic VOC abatement. J. Hazard. Mater. 195: 30-54.

Wang, H., Guo, H., Zhang, N., Chen, Z., Hu, B. and Wang, X. (2019a). Enhanced photoreduction of U (VI) on $\mathrm{C}_{3} \mathrm{~N}_{4}$ by $\mathrm{Cr}$ (VI) and bisphenol A: ESR, XPS and EXAFS investigation. Environ. Sci. Technol. 53: 6454-6461.

Wang, H., Li, Q., Zhang, S., Chen, Z., Wang, W., Zhao, G. and Wang, X. (2019b). Visible-light-driven $\mathrm{N}_{2}-g-\mathrm{C}_{3} \mathrm{~N}_{4}$ as a highly stable and efficient photocatalyst for bisphenol $\mathrm{A}$ and $\mathrm{Cr}$ (VI) removal in binary systems. Catal Today 335: $110-116$.

Wang, M., Guo, P., Chai, T., Xie, Y., Han, J., You, M., Wang, Y. and Zhu, T. (2017). Effects of Cu dopants on the structures and photocatalytic performance of cocoonlike $\mathrm{Cu}-\mathrm{BiVO}_{4}$ prepared via ethylene glycol solvothermal method. J. Alloy. Compd. 691: 8-14.

Wang, Y., Long, Y. and Zhang, D. (2016). Novel bifunctional $\mathrm{V}_{2} \mathrm{O}_{5} / \mathrm{BiVO}_{4}$ nanocomposite materials with enhanced antibacterial activity. J. Taiwan Inst. Chem. Eng. 68: 387-395.

Xia, L., Bai, J., Li, J., Zeng, Q., Li, L. and Zhou, B. (2017). High-performance $\mathrm{BiVO}_{4}$ photoanodes cocatalyzed with an ultrathin a- $\mathrm{Fe}_{2} \mathrm{O}_{3}$ layer for photoelectrochemical application. Appl. Catal. B 204: 127-133.

Xiao, H., Qi, C., Cheng, Q., Dou, C., Ning, X. and Ru, Y. (2018). Experimental and modeling studies of $\mathrm{SO}_{3}$ homogeneous formation in the post-flame region. Aerosol Air Qual. Res. 12: 2939-2947.

Xing, B., Chen, T., Liu, H., Qing, C., Xie, J. andXie, Q. (2017). Removal of phosphate from aqueous solution by activated siderite ore: Preparation, performance and mechanism. J. Taiwan Inst. Chem. Eng. 80: 875-882.

Yan, X., Sun, Y., Zhu, T. and Fan, X. (2013). Conversion of carbon disulfide in air by non-thermal plasma. $J$. Hazard. Mater. 261: 669-674.

Yang, C., Gao, G., Guo, Z., Song, L., Chi, J. and Gan, S. (2017b). Two-step hydrothermal synthesis of novel hierarchical $\mathrm{Co}_{3} \mathrm{O}_{4} / \mathrm{Bi}_{2} \mathrm{O}_{2} \mathrm{CO}_{3} p$ - $n$ heterojunction composite photocatalyst with enhanced visible light photocatalytic activity. Appl. Surf. Sci. 400: 365-374.

Yang, F., Wang, Y., Li, H., Yang, M., Li, T., Cao, F., Chen, J. and Wang, Z. (2017a). Influence of cloud/fog on atmospheric VOCs in the free troposphere: A case study at Mount Tai in eastern China. Aerosol Air Qual. Res. 10: 2401-2412.

Yu, Q., Tang, Z.R. and Xu, Y.J. (2014). Synthesis of BiVO nanosheets-graphene composites toward improved visible light photoactivity. J. Energy Chem. 23: 564-574.

Yuan, H., Liu, J., Li, J., Li, Y., Wang, X., Zhang, Y., Jiang, J., Chen, S., Zhao, C. and Qian, D. (2015). Designed 
synthesis of a novel $\mathrm{BiVO}_{4}-\mathrm{Cu}_{2} \mathrm{O}-\mathrm{TiO}_{2}$ as an efficient visible-light-responding photocatalyst. $J$. Colloid Interface Sci. 444: 58-66.

Zhao, J., Lu, Q., Wei, M. and Wang, C. (2015). Synthesis of one-dimensional $\alpha-\mathrm{Fe}_{2} \mathrm{O}_{3} / \mathrm{Bi}_{2} \mathrm{MoO}_{6}$ heterostructures by electrospinning process with enhanced photocatalytic activity. J. Alloys Compd. 646: 417-424.

Zhao, W., Wang, Y., Yang, Y., Tang, J. and Yang, Y. (2012). Carbon spheres supported visible-light-driven $\mathrm{CuO}-\mathrm{BiVO}_{4}$ heterojunction: Preparation, characterization, and photocatalytic properties. Appl. Catal. B 115: 90-99.

Zhao, Y., Cui, K., Chen, S., Yin, Z., Chao, H. and Chien, G.P.C. (2018). Atmospheric $\mathrm{PM}_{2.5}$, total PCDD/Fs$\mathrm{WHO}_{2005}$-TEQ level and wet deposition: Cases of Jinan and Weihai cities, China. Aerosol Air Qual. Res. 12:
3081-3095.

Zhu, C., Lu, J., Wang, X., Qin, H., Li, H. and Wang, J. (2013). Removal of carbon disulfide from gas streams using dielectric barrier discharge plasma coupled with $\mathrm{MnO}_{2}$ catalysis system. Plasma Chem. Plasma Process. 33: 569-579.

Zou, X., Chen, T., Zhang, P., Chen, D., Liu, H. and Qing, C. (2013). Structural characteristic of natural goethite by thermal treatment. J. Chin. Ceram. Soc. 41: 1442-1446.

Received for review, August 3, 2019 Revised, September 16, 2019 Accepted, September 17, 2019 